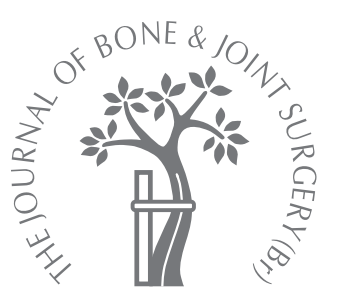

C. J. Pendegrass,

M. J. Oddy,

S. Sundar,

S. R. Cannon,

A. E. Goodship,

G. W. Blunn

From The Institute of

Orthopaedics and

Musculoskeletal

Science, Stanmore,

England

C. J. Pendegrass, BSc, PhD,

Research Fellow

M. J. Oddy, MA, MSc, MRCS,

Research Fellow

S. Sundar, BSc, PhD Student

a. W. Blunn, BSc, PhD,

Professor

The Centre for Biomedical

Engineering

S. R. Cannon, FRCS

Consultant Orthopaedic

Surgeon

Royal National Orthopaedic

Hospital

A. E. Goodship, BVSc, PhD,

MRCVS, Professor

Institute of Orthopaedics \&

Musculoskeletal Science

Brockley Hill, Stanmore,

Middlesex HA7 4LP, UK.

Correspondence should be sent to Dr C. J. Pendegrass; e-mail: c.pendegrass@ucl.ac.uk

(c)2006 British Editorial Society of Bone and Joint Surgery doi:10.1302/0301-620X.88B9. $17748 \$ 2.00$

$J$ Bone Joint Surg $[\mathrm{Br}]$ 2006;88-B:1245-51.

Received 7 February 2006; Accepted 12 April 2006

\title{
The novel use of resorbable Vicryl mesh for in vivo tendon reconstruction to a metal prosthesis
}

\begin{abstract}
We examined the mechanical properties of Vicryl (polyglactin 910) mesh in vitro and assessed its use in vivo as a novel biomaterial to attach tendon to a hydroxyapatite-coated metal implant, the interface of which was augmented with autogenous bone and marrow graft. This was compared with tendon re-attachment using a compressive clamp device in an identical animal model. Two- and four-ply sleeves of Vicryl mesh tested to failure under tension reached $5.13 \%$ and $28.35 \%$ of the normal ovine patellar tendon, respectively. Fourply sleeves supported gait in an ovine model with $67.05 \%$ weight-bearing through the operated limb at 12 weeks, without evidence of mechanical failure.

Mesh fibres were visible at six weeks but had been completely resorbed by 12 weeks, with no evidence of chronic inflammation. The tendon-implant neoenthesis was predominantly an indirect type, with tendon attached to the bone-hydroxyapatite surface by perforating collagen fibres.
\end{abstract}

The replacement of large bony skeletal segments in tumour and revision arthroplasty requires the attachment of tendons to enable function. The ability to achieve sound fixation of soft tissues to metal would be a significant advance. The methods currently employed include direct mechanical clamping of the soft tissues, ${ }^{1}$ fixation via loops on the prostheses ${ }^{2}$ and non-absorbable augmentation materials. ${ }^{3-6}$ Experimental research in this field has been directed towards creating a neoenthesis using combinations of implant surface characteristics, bone and marrow grafts and, recently, recombinant human osteogenic protein-1.-11 We have used tendon clamping devices with an interlocking spike mechanism to provide adequate mechanical stability for the construct. ${ }^{7,8}$

Rempel and Abrahamsson ${ }^{12}$ demonstrated that under hypoxic conditions tendon explants showed significantly reduced collagen synthesis. Tissue oxygen tensions of $20 \mathrm{mmHg}$ to $30 \mathrm{mmHg}$ have been shown to be required for the secretion of collagen by fibroblasts ${ }^{13}$ and are also necessary for energy-dependent metabolic processes, cell proliferation and epithelialisation. ${ }^{14,15}$ We believe that the current advances in interface biology might therefore be more successful if appropriate mechanical stability could be achieved without physical compression of the soft tissues.

Absorbable and non-absorbable meshes have been investigated and are currently being used as augmentation materials in both orthopaedic and non-orthopaedic fields. ${ }^{16-23}$ Vicryl (polyglactin 910) mesh (Johnson and Johnson Intl., St. Stevens-Woluwe, Belgium) is an uncoated, undyed synthetic copolymer that comprises $90 \%$ glycolide and $10 \%$ l-lactide, and is both inert and non-antigenic. ${ }^{24-26} \mathrm{It}$ is reported to be totally resorbed after 60 to 90 days in vivo, and is supplied as a knitted mesh with a single layer tensile strength of $250 \mathrm{~N}$, used as a scaffold during soft-tissue healing.

In this study we tested the hypothesis that a tendon can be attached to a metal implant using Vicryl mesh, which with biological augmentation will support the development of an interface having superior mechanical and biological properties to those of a compressive soft-tissue clamp.

\section{Materials and Methods}

In vitro investigations. Single sheets of Vicryl mesh were folded into two-ply and four-ply sleeves, $40 \mathrm{~mm} \times 25 \mathrm{~mm}$ in dimension. The ends of the sleeves were clamped between the plates of a Zwick (Zwick GmbH \& Co., Ulm, Germany) (Fig. 1) mechanical testing machine and were tested to failure under tension at a rate of $200 \mathrm{~mm}$ per minute without preconditioning. Intact patella-patellar tendon-proximal tibia specimens were harvested from skeletally mature fresh cadaver Friesland ewes (65 $\mathrm{kg}$ to $85 \mathrm{~kg}$ ) and were held in customised jigs for testing using the same procedure. 


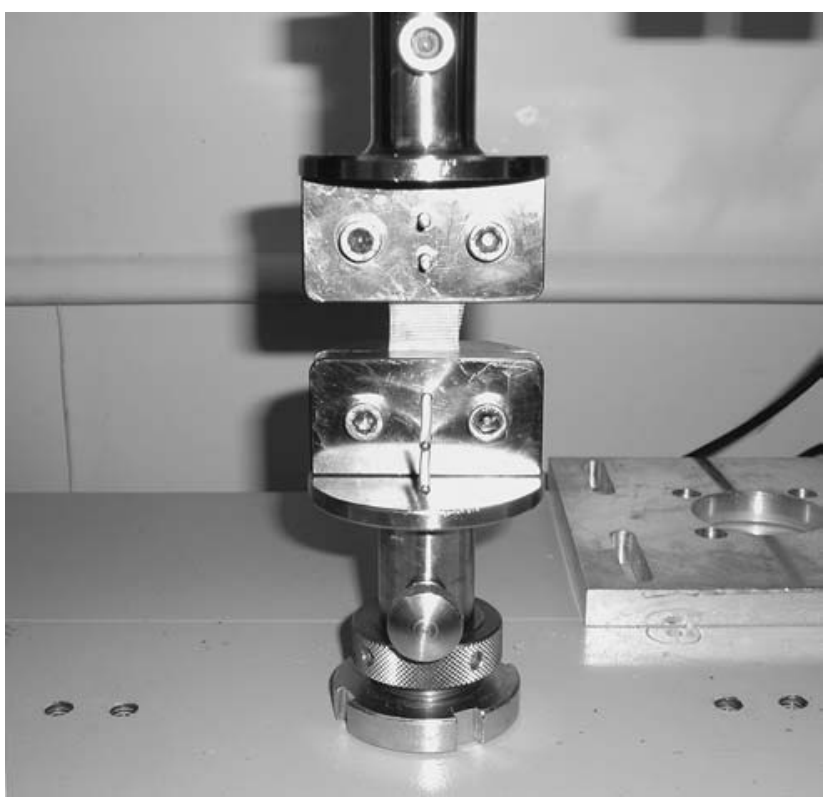

Fig. 1

A four-ply mesh construct undergoing mechanical testing under tension to failure on a Zwick mechanical testing machine.

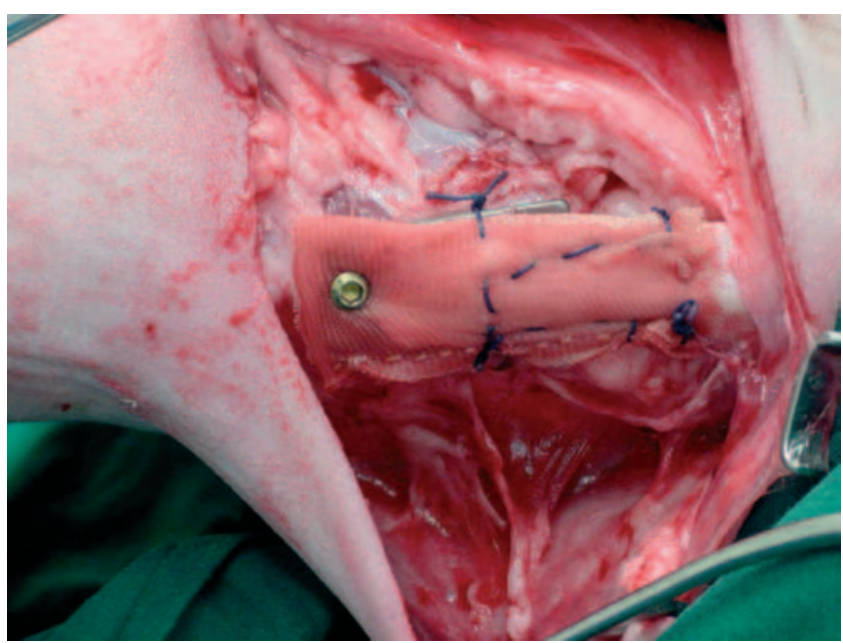

Fig. 2

Patellar tendon attached with a four-ply mesh sleeve.

In vivo study. The study was approved under the UK Home Office Animals (Scientific Procedures) Act 1986.

Implant. A customised titanium alloy (Ti-6A1-4V) base plate $(30 \mathrm{~mm}$ in length) was produced to simulate the extramedullary surface of a proximal tibial replacement. It was plasma-sprayed with a $70 \mu \mathrm{m}$ coating of CAPITAL Hydroxyapatite (HA) (Plasma Biotal Limited, Tideswell,
United Kingdom). The base plate had six press-fit spikes (1 $\mathrm{mm}$ in diameter and $4 \mathrm{~mm}$ in length) as anchor sites for the tendon in the mesh sleeve.

Study design. We used eight skeletally-mature Friesland ewes, weighing between $65 \mathrm{~kg}$ and $85 \mathrm{~kg}$ (mesh group). The patellar tendon was attached to the surface of a metal implant using a four-ply sleeve of Vicryl mesh (Fig. 2) supplied sterile (by ethylene oxide) from the distributor. The tendon-implant interface was augmented by an autogenous cancellous bone and marrow graft. Two animals were killed six weeks after the operation and the tendon-implant interfaces were examined histologically. The remaining six animals in the mesh group were killed at 12 weeks. The results were compared to those of a previously reported experimental group of six animals in which the patellar tendon was attached to a custom-made metal implant using a spiked compressive H-shaped clamp lid, with the interface biologically augmented with an autogenous bone and marrow graft of similar wet weight and consistency (autograft group). ${ }^{7,8}$ The mesh and autograft groups were compared histologically with intact patellar tendon insertions from the non-operated hindlimb of the autograft group. Data from the operated and un-operated hindlimbs was collected in a previous study. ${ }^{8}$

Surgery. The animals were given a subcutaneous premedication injection of xylazine hydrochloride $(0.2 \mathrm{mg} / \mathrm{kg}$; Bayer plc, Bury St. Edmunds, United Kingdom). Anaesthesia was induced using intravenous midazolam $(2.5 \mathrm{mg}$ stat dose; Roche Products Limited, Welwyn Garden City, United Kingdom) and ketamine hydrochloride $(2 \mathrm{mg} / \mathrm{kg}$; Fort Dodge Animal Health Ltd., Southampton, United Kingdom) and was maintained with halothane 3\% (Merial Animal Health Ltd., Harlow, United Kingdom) and oxygen (4 1/min). The right patellar tendon was defined and elevated from the tibial tuberosity. An osteotomy was performed at the insertion site to create a flat bone bed to which the base plate was attached using two $2.7 \mathrm{~mm}$ selftapping cortical bone screws (Synthes, Stratec Medical Ltd., Welwyn Garden City, United Kingdom). A single layer of Vicryl mesh was laid on the base plate, onto which a slurry of autogenous cancellous bone chips and marrow (1.5 g wet weight), harvested from the ipsilateral iliac crest, was packed along the whole length of the HA-coated surface of the implant. In the mesh group the patellar tendon was sutured using Vicryl between the middle layers of a four-ply sleeve of Vicryl mesh using size 0 Vicryl. The tendon-mesh construct was pressed on to the base plate spikes and held with a single screw through the distal extent of the mesh sleeve; the whole construct was sealed to retain the graft by suturing the outer extensions of the base layer of mesh together. The animals were given subcutaneous doses of ceftiofur antibiotic $(1 \mathrm{mg} / \mathrm{kg}$; Pharmacia \& Upjohn, Stockholm, Sweden) intra-operatively and for five postoperative days, and intramuscular buprenorphine hydrochloride $(10 \mu \mathrm{g} / \mathrm{kg}$; Reckitt \& Colman Products Ltd., Melton Mowbray, United Kingdom) for one post-operative 
day. The animals were allowed to mobilise freely within a pen ( $3 \mathrm{~m} \mathrm{x} 4 \mathrm{~m})$.

Force plate. The animals underwent force plate assessment (Kistler Biomechanics Limited, Alton, United Kingdom) pre-operatively, and after six and 12 weeks. The data from 12 passages over the force plate were collected for each hindlimb for each animal. Using in-house custom-written software, the mean peak vertical ( $z$ coordinate) component of the ground reaction force (GRF), normalised for the weight of the animal ( $\mathrm{F}_{\max }$ /weight), was obtained for both hindlimbs. We calculated the mean right hindlimb peak vertical $\left(\mathrm{F}_{\mathrm{z}}\right)$ GRF as a percentage of the mean left hindlimb peak vertical $\left(F_{z}\right)$ GRF (operated/non-operated as a percentage), and this was expressed as functional weight-bearing. Comparisons were made between the experimental groups at six and 12 weeks. The change in post-operative $\mathrm{F}_{\max } /$ weight between six and 12 weeks was also determined.

Histological analysis. The operated patella-patellar tendonimplant specimens were harvested and fixed in 10\% formalin for ten days. The samples underwent ascending graded alcohol dehydration, defatting in chloroform for five days, and embedding in LR White Hard Grade Resin (London Resin Company Limited, Reading, United Kingdom). The sections were cut, ground, and polished to $100 \mu \mathrm{m}$ thickness, stained with toluidine blue and paragon, and underwent qualitative morphological assessment using an Olympus BH2 microscope (Olympus Optical Company Limited, Tokyo, Japan) linked to Zeiss KS300 3.0 image analysis software (Imaging Associates, Thame, United Kingdom). Three sections at one-third width intervals across the tendon-implant specimen were prepared for each animal. For each section, five fields of view along the length of the base plate were observed at a magnification of x100. Using Adobe Photoshop version 6.0.1 (Adobe Systems Inc., San Jose, California), a double-blind quantitative analysis of collagen fibre orientation at the implant surface was performed by measuring the angles of elevation of the collagen fibres per field of view, with respect to the whole length of the HA-coated base plate. The orientation of the collagen fibres in the normal patellar tendonbone enthesis was similarly measured, using the tangent to the surface of the tibial tuberosity as a reference point. Comparisons were made between the mesh group, the autograft group, and the non-operated limbs of the autograft group (intact group). Morphological comparisons were also performed between the experimental and intact groups.

Statistical analysis. Numerical data were entered through SPSS version 12.0 for Windows (SPSS Inc., Chicago, Illinois) and analysed using non-parametric tests. The MannWhitney $U$ test was used to examine differences between the in vitro mechanical testing data and the force plate functional weight-bearing and quantitative histological data. The Wilcoxon signed-rank test was used to examine differences in functional weight-bearing status between six

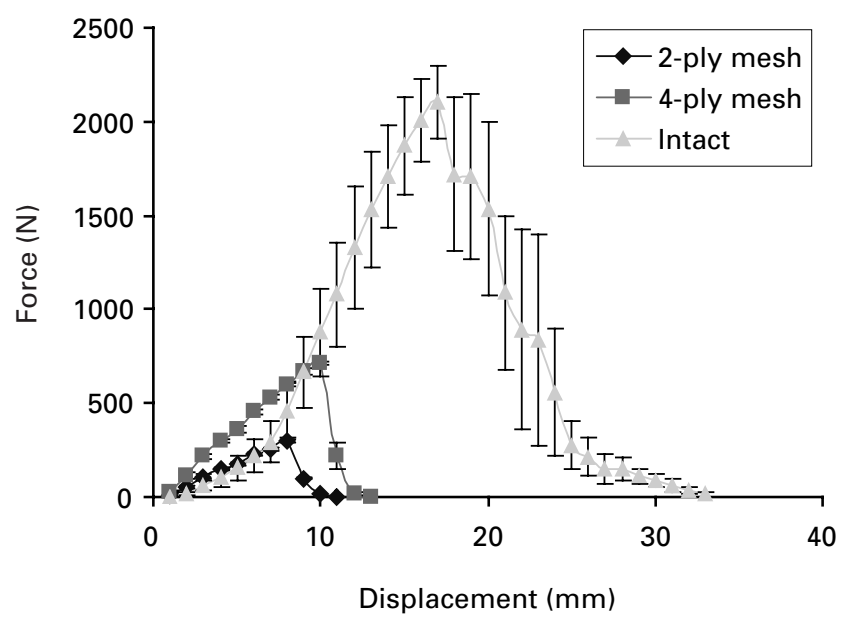

Fig. 3

Force-displacement graph for two- and four-ply mesh constructs and intact patellar tendon specimens.

and 12 weeks post-operation between groups. A result of $\mathrm{p}<0.05$ was considered to be significant.

\section{Results}

In vitro investigations. Under loading, all of the mesh sleeves failed in their mid-substance. The median values (with $95 \%$ confidence intervals (CI)) of stress at failure were $129.12 \mathrm{~N}$ (68.32 to 212.10 ), and $713.32 \mathrm{~N}$ (681.68 to $744.95)$ for the two-ply and four-ply sleeves, respectively. The intact fresh cadaveric patella-patellar tendon-proximal tibia samples failed in their mid-substance at $2516.2 \mathrm{~N}$ (2272.32 to 2974.78 ), which was significantly higher than the four-ply mesh sleeve results $(\mathrm{p}=0.004)$ (Fig. 3). Twoand four-ply sleeves of Vicryl mesh tested to failure under tension reached $5.13 \%$ and $28.35 \%$ of the normal ovine patellar tendon, respectively.

In vivo study. All of the animals recovered from surgery well, and mobilised freely post-operatively. There was no infection or failure due to pull-out. At six weeks, the functional weight-bearing results (percentage operated/control limb - median with $95 \% \mathrm{CI})$ were $66.73 \%(51.40 \%$ to $79.40 \%)$ and $46.91 \%(35.22 \%$ to $54.11 \%)$ for the autograft and mesh groups, respectively $(\mathrm{p}=0.016)$, while at 12 weeks the results were $90.55 \%$ (58.99\% to $101.36 \%)$ and $67.05 \%(50.68 \%$ to $87.45 \%)$ for the autograft and mesh groups, respectively $(\mathrm{p}=0.201)$.

The differences in functional weight-bearing status for the operated limb between six and 12 weeks $\left(\mathrm{F}_{\max } /\right.$ weight $)$ (median with 95\% CI) were 4.61 (2.91 to 7.72 ) and 7.07 (3.93 to 10.13) for the autograft and mesh groups, respectively ( $p=0.345$ ) (Fig. 4). For the non-operated limb the values were $-2.37(-7.61$ to 4.06$)$ and $-12.82(-20.07$ to $-5.03)$ for the autograft and mesh groups, respectively $(\mathrm{p}=$ 0.043) (Fig. 4). 


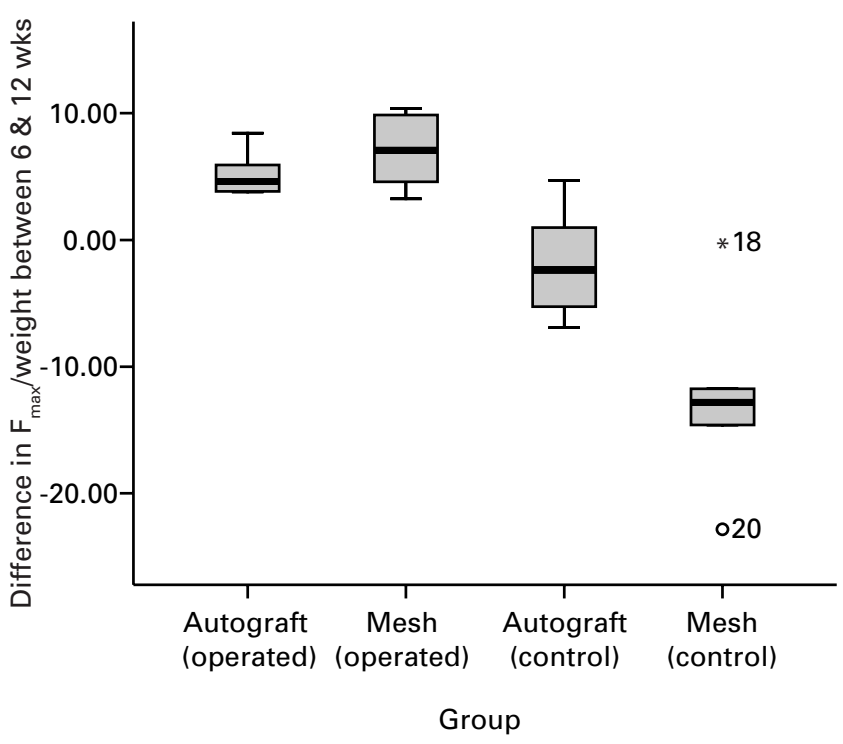

Fig. 4

Box-and-whiskers plot showing the different in $\mathrm{F}_{\max } /$ weight between six and 12 weeks for the operated and non-operated hindlimbs (*/o outlying data points indicating that 2 data points lie outside the interquartile range).

Histology. The normal patellar tendon insertion consisted of normal tendon attached via a layered direct-type enthesis. ${ }^{8,27}$ The median angle (with $95 \% \mathrm{CI}$ ) of collagen fibre orientation tangential to the insertion was $33.00^{\circ}\left(29.58^{\circ}\right.$ to $40.24^{\circ}$ ). Macroscopically, the mesh group samples consisted of a dense collagenous attachment continuous from the patella to the implant base plate, with no evidence of failure due to pull-out. At six weeks, the tendon consisted of a dense collagenous connective tissue with parallelorientated fibres displaying a crimp pattern similar to that of the normal tendon. At the periphery of the tendon the mesh fibres were observed clearly, with interweaving collagen fibres and a low-density inflammatory cell infiltrate of lymphocytes and macrophages (Fig. 5a). At the implant surface there was poor retention of the morcellised graft, which was seen both intimately associated with the HA surface and also within the tendon. The regions of tendonbone interface were disorganised and it was impossible to make quantitative measures of fibre orientation (Fig. 5b). In areas where the morcellised graft had been poorly retained, the tendon-HA interface showed predominantly fibrous tissue encapsulation with a dense collagenous layer which was orientated parallel to the implant surface.

At 12 weeks no mesh fibres were observed and there was no evidence of a residual chronic inflammatory process. The tendon substance was normal and the tendon-bone interface regions had reorganised. The interface showed predominantly an indirect-type of enthesis, with Sharpeylike collagen fibres spanning between tendon and bone (Fig. 5c). Fibrocartilage-containing regions were also observed, displaying characteristics more like those of a normal direct-type enthesis (Fig. 5d). The interface in the autograft group has been previously described at 12 weeks as a layered tendon-fibrocartilage-bone-HA attachment resembling an indirect enthesis. ${ }^{8}$ The angles (median with 95\% CI) of collagen fibre orientation tangential to the implant surface were $17.80^{\circ}\left(14.25^{\circ}\right.$ to $\left.18.76^{\circ}\right)$ and $28.30^{\circ}\left(26.62^{\circ}\right.$ to $35.04^{\circ}$ ) for the autograft and mesh groups, respectively. The orientation angles were significantly greater for the mesh and intact groups than for the autograft group ( $\mathrm{p}=$ $0.000)$. No significant difference was observed between the mesh and intact groups $(\mathrm{p}=0.087)$.

\section{Discussion}

We have previously reported the initial investigations using ea prototype tendon clamp and shown tissue necrosis in vivo, owing to the prevention of vascularisation because of the combination of mechanical pressure and inadequate exposure. ${ }^{7}$ Subsequent modifications to the lid of the clamp to an $\mathrm{H}$ shape with perforations allowed more access from overlying vascular tissue, while providing the same mechanical fixation. Augmentation of the tendon-implant interface with autogenous bone and marrow graft supported the development of a neoenthesis. ${ }^{7}$ This device provides adequate mechanical stability to allow early mobilisation during biological development of the neoenthesis. ${ }^{8}$ At 12 weeks the resulting enthesis contained regions of both direct and indirect-type insertions. ${ }^{7} \mathrm{We}$ hypothesised that if non-compressive tendon fixation could be achieved, thus allowing an open environment for healing, a mechanically and biologically superior enthesis might develop compared with the closed clamp system.

Previous studies have reported the development of immature tendon-bone-implant entheses when compressive forces are applied with a clamp device. ${ }^{8,10,11,28}$ The detrimental effects of compression on tissue healing are well established and include ischaemia resulting from increased pressure, reduced microvascular flow, and limited delivery and removal of cellular substrates and metabolites, respectively, ${ }^{12}$ and reduced oxygen tension limiting cell proliferation, proteoglycan and protein synthesis. ${ }^{13,14}$

The mesh provided adequate mechanical support in vivo to allow gait, and matched the predicted values expected from the testing in vitro, where the construct failed in the region of $700 \mathrm{~N}$. Using an implantable patellar tendon transducer, Korvick et $\mathrm{al}^{29}$ demonstrated in a goat model that in normal walking, the tendon experiences a maximum force of about $800 \mathrm{~N}$. We selected a four-ply sleeve, with the tendon between the middle layers, to minimise the volume of material between tendon and the graft retained by the basal mesh layer overlying the implant. Because we did not experience any in vivo failures we feel that this sleeve is a sufficient attachment; however, we appreciate that further in vitro testing is necessary, as well as similar mechanical studies of the tendon-clamp construct. The animals in the mesh group did compensate with increased weight-bearing 


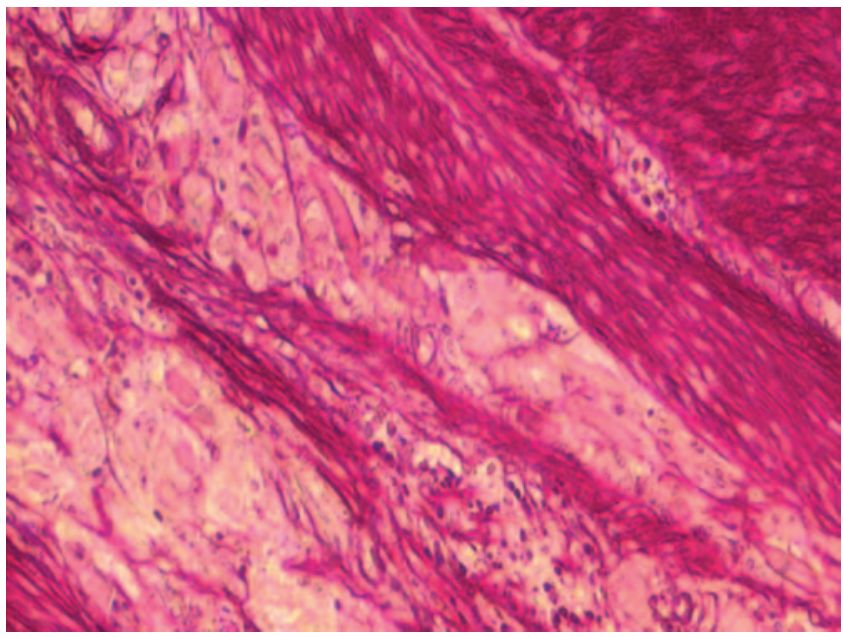

Fig. 5a

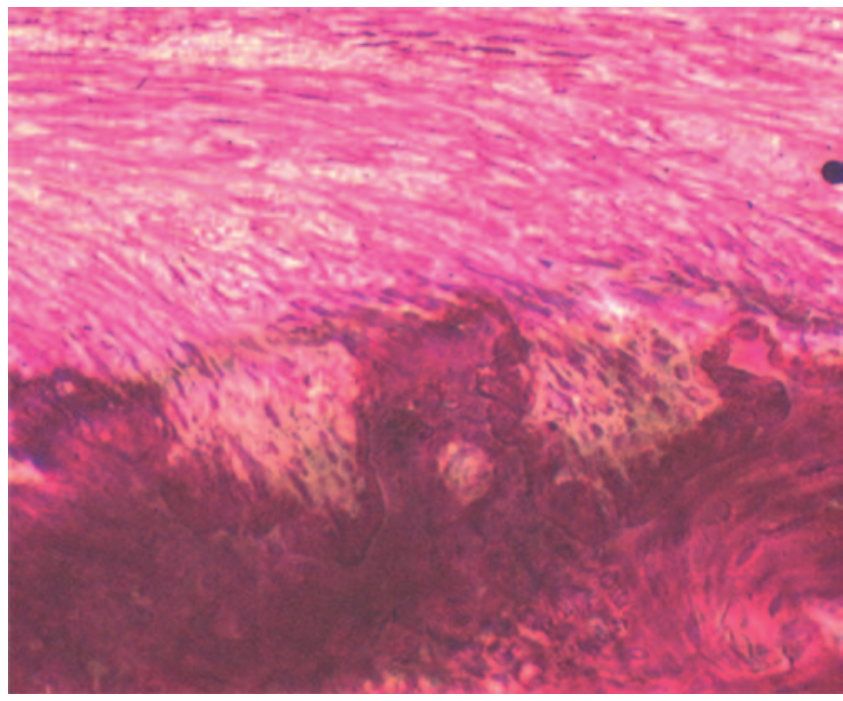

Fig. 5c

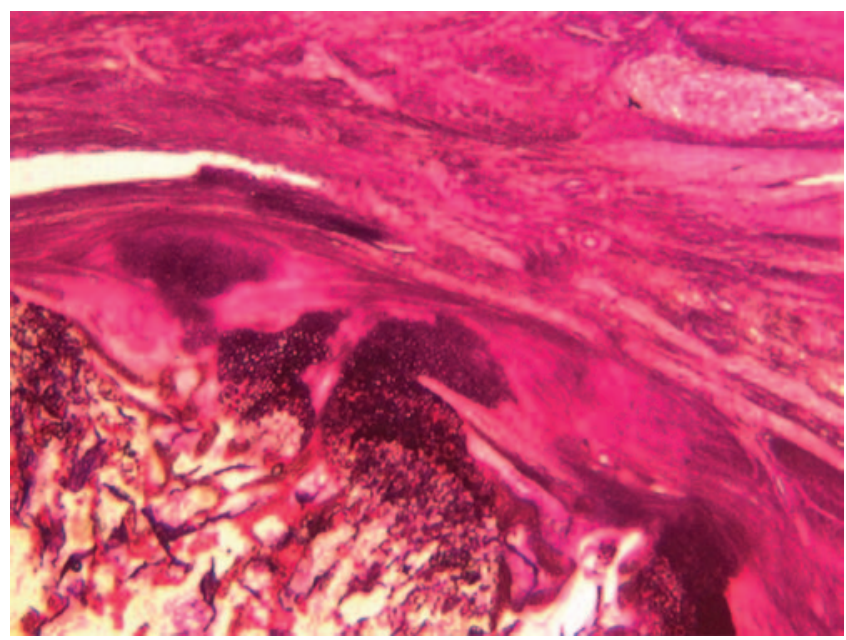

Fig. 5b

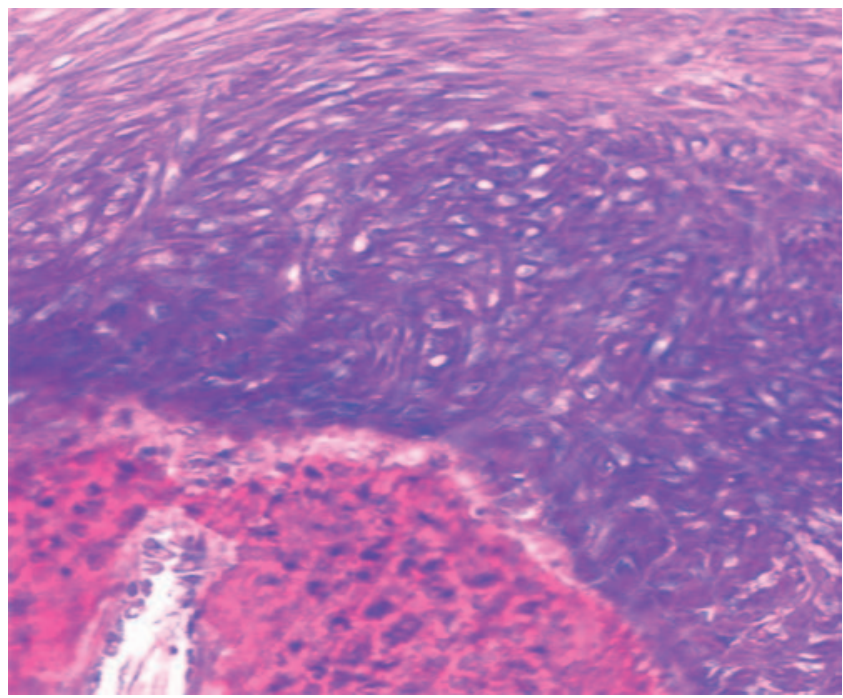

Fig. 5d

Photomicrographs showing a) collagen/mesh fibres interweaving in the peripheral tendon in the mesh group at six weeks (toluidine blue and paragon, $x 50)$, b) the tendon-bone interface in the mesh group at six weeks (toluidine blue and paragon x 10), c) the indirect-type tendon-bone enthesis with Sharpey-like fibres spanning the interface in the mesh group at 12 weeks (toluidine blue and paragon, $x$ 50), and d) the fibrocartilage-containing directtype enthesis in the mesh group at 12 weeks (toluidine blue and paragon, $\times 50$ ).

through the contralateral non-operated limb after six weeks in vivo. By 12 weeks, compensation by the nonoperated limb was reduced but still observed in the mesh group, although despite this, no significant difference in functional weight-bearing was observed between the groups at this time point.

The orientation of the collagen fibres in a normal enthesis varies with the contour of the tibial tuberosity. Variation in fibre orientation with respect to the bone-implant surface has been shown to reflect the type and integrity of the resulting attachment. ${ }^{30}$ We accept that the osteotomy angle may have contributed to changing the local mechanical environment, and that this may have influenced our findings; however, the mean angle of insertion in the mesh group was not significantly different from that in the intact controls. The regions of less-organised indirect-type enthesis consisted of more perpendicularly orientated fibres perforating the bone, whereas in the more organised direct-type enthesis the collagen fibres approach the insertions at a more shallow angle. In addition, it has been shown that a tendon-HA attachment develops with collagen fibres orientated parallel to the implant surface, indicative of fibrous encapsulation. ${ }^{7,8}$ We observed that the mesh group contained regions of both indirect-type enthesis and of tissue encapsulation, and the resulting median collagen fibre orientation angle reflects this, as 
opposed to being truly representative of the degree of maturation of the neoenthesis. The lack of significant difference between the mesh and intact group specimens could therefore be coincidental.

We postulate that the less compressive environment in the mesh group fixation was responsible for the lower degree of fibrocartilaginous tissue observed compared with the autograft group. ${ }^{8}$ Hence the predominantly tensile forces in the mesh group attachment led to the development of a more fibrous indirect enthesis. A longer term study is required to determine whether the mesh group interface would remodel into a direct-type enthesis, as observed in previous tendon-bone tunnel healing models. ${ }^{31}$ Lack of mechanical compression did result in poorer graft retention, and we believe that a further study using a bone block should overcome this problem.

The biocompatibility and applications of polylactic acid and polyglycolic acid copolymers have been previously reviewed by Athanasiou et al. ${ }^{26}$ They emphasised that most studies have demonstrated no toxicity, minimal evidence for local tissue inflammation or host reaction, and indeed in some cases the copolymers have been implicated in accelerated fracture healing, making them attractive materials for 'delivery vehicles, grafts and scaffolds for neo-tissue growth'. More recent work has demonstrated that polylactide/glycolide polymers show better tenocyte adhesion strength when modified with extracellular matrix cell adhesion proteins, including fibronectin and type I collagen. ${ }^{32}$ However, a negative effect due to a weak inflammatory response and the acidic environment resulting from polymer degradation could prove detrimental to progenitor cells involved in the healing environment. ${ }^{33}$ Roberts et $\mathrm{al}^{20}$ used polyglactin mesh experimentally in a model of acute Achilles tendon lacerations in a rabbit showing mild diffuse lymphocytic infiltrate and no discernible evidence of the biomaterial at 20 weeks, but equally no perceived advantage mechanically compared to direct suture repair. Cao et $\mathrm{al}^{34}$ used polyglycolic acid for tendon engineering in a hen model and observed a residual inflammatory reaction at eight weeks, with degradation of the biomaterial. The neotendon appeared normal by 14 weeks, with a breaking strength of $83 \%$ of normal. Sato et $\mathrm{al}^{35}$ used braided polylactic acid fibres woven as a neotendon in a rabbit model for Achilles tendon reconstruction, showing a mean strength compared with the intact side of $61 \%$ at 26 weeks, and good integration with type I and III collagen-containing fibrous tissue.

The Vicryl mesh used in this study provided a novel means of attaching a tendon to a HA-coated metal implant, with potential useful clinical implications. It provided sufficient initial mechanical fixation to enable early mobilisation and weight-bearing at 12 weeks, not significantly different from a mechanical clamp. Despite the potential detrimental effects of the mesh degradation products, an enthesis developed with regions of both direct and indirect types at 12 weeks. Poor retention of morcellised graft could be reduced using a bone block. This requires further investigation.

No benefits in any form have been received or will be received from a commercial party related directly or indirectly to the subject of this article.

\section{References}

1. Cannon SR. Massive prostheses for malignant bone tumours of the limbs. J Bone Joint Surg [Br] 1997;79-B:497-506.

2. Bickles J, Wittig JC, Kollender Y, et al. Reconstruction of the extensor mechanism after proximal tibia endoprosthetic replacement. J Arthroplasty 2001;16:856-62.

3. Malawer MM, McHale KA. Limb sparing surgery for high-grade malignant tumours of the proximal tibia: surgical technique and a method of extensor mechanism reconstruction. Clin Orthop 1989;239:231-48.

4. Eckardt JJ, Matthews JG 2nd, Eilber FR. Endoprosthetic reconstruction after bone tumour resections of the proximal tibia. Orthop Clin North Am 1991;22:149-60.

5. Ozaki T, Kunisada T, Kawai A, Takahara Y, Inoue H. Insertion of the patella tendon after prosthetic replacement of the proximal tibia. Acta Orthop Scand 1999;70: 527-9.

6. Gosheger G, Hillman A, Lindner $\mathbf{N}$, et al. Soft tissue reconstruction of megaprostheses using a trevira tube. Clin Orthop 2001;393:264-71.

7. Pendegrass CJ, Oddy MJ, Cannon SR, et al. A histomorphological study of tendon reconstruction to a hydroxyapatite-coated implant: regeneration of a neo-enthesis in vivo. J Orthop Res 2004;22:1316-24.

8. Oddy MJ, Pendegrass CJ, Goodship AE, et al. Extensor mechanism reconstruction after proximal tibial replacement. J Bone Joint Surg [Br] 2005;87-B:873-8.

9. Higuera CA, Inoue N, Lim JS, et al. Tendon reattachment to a metallic implant using an allogenic bone plate augmented with rhOP-1 vs. autogenous cancellous bone and marrow in a canine model. J Orthop Res 2005;23:1091-9.

10. Gottsauner-Wolf F, Egger EL, Schultz FM, Sim FH, Chao EY. Tendons attached to prostheses by tendon-bone block fixation: an experimental study in dogs. J Orthop Res 1994;12:814-21.

11. Inoue N, Ikeda K, Aro $\mathbf{H}$, et al. Biologic tendon fixation to metallic implant augmented with autogenous cancellous bone graft and bone marrow in a canine model. $J$ Orthop Res 2002;20:957-66.

12. Rempel D, Abrahamsson So. The effects of reduced oxygen tension on cell proliferation and matrix synthesis in synovium and tendon explants from the rabbit carpel tunnel: an experimental study in vitro. J Orthop Res 2001;19:143-8.

13. Guyton GP, Saltzman CL. The diabetic foot: basic mechanisms of disease. J Bone Joint Surg [Am] 2001;83-A:1084-96

14. Hunt TK, Pai MP. The effect of varying ambient oxygen tensions on wound metabolism and collagen synthesis. Surg Gynecol Obstet 1972;135:561-7.

15. Ehrlichman RJ, Seckel BR, Bryan DJ, Moschella CJ. Common complications of wound healing: prevention and management. Surg Clin North Am 1991;71:1323-51.

16. Balshi JT, Hernandez RE, Cutler RH, Hertzog CF. Treatment of osseous defects using Vicryl mesh (polyglactin 910) and the Branemark implant: a case report. Int J Oral Maxillofac Implants 1991;6:87-91.

17. Giannini S, Girolami M, Ceccarelli F, Catani F, Stea S. Surgical repair of Achilles tendon ruptures using polypropylene braid augmentation. Foot Ankle Int 1994;15: $372-5$

18. Kdolsky RK, Gibbons DF, Kwasny 0, Schabus R, Plenk H. Braided polypropylene augmentation device in reconstructive surgery of the anterior cruciate ligament: longterm clinical performance of 594 patients and short-term arthroscopic results, failure analysis by scanning electron microscopy and synovial histomorphology. J Orthop Res 1997;15:1-10.

19. Ozaki J, Fujiki J, Sugimoto K, Tamai S, Masuhara K. Reconstruction of neglected Achilles tendon rupture with marlex mesh. Clin Orthop 1989;238:204-8.

20. Roberts JM, Goldstrohm GL, Brown TD, Mears DC. Comparison of unrepaired, primarily repaired and polyglactin mesh reinforced Achilles tendon lacerations in rabbits. Clin Orthop 1983;181:244-9

21. Buchsbaum HS, Christopherson W, Lifshitz S, Bernstein S. Vicryl mesh in pelvic floor reconstruction. Arch Surg 1985;120:1389-91.

22. Shinhar D, Finaly R, Niska A, Mares AJ. The use of collagen-coated vicryl mesh for reconstruction of the canine cervical oesophagus. Pediatr Surg Int 1998;13:84-7.

23. Tobias AM, Low DW. The use of subfascial Vicryl mesh buttress to aid in the closure of massive hernias following damage control laparotomy. Plast Reconstr Surg 2003; 112:766-76.

24. Durselen L, Dauner M, Hierlemann H, et al. Resorbable polymer fibres for ligament augmentation. J Biomed Mater Res 2001;58:666-72.

25. Laitinen 0, Tormala P, Taurio R, et al. Mechanical properties of biodegradable ligament augmentation device of poly (L-lactide) in vitro and in vivo. Biomaterials 1992; 13:1012-16. 
26. Athanasiou KA, Niederauer GG, Agrawal CM. Sterilization, toxicity, biocompatbility and clinical applications of polylactic acid/polyglycolic and copolymers. Biomaterials 1996;17:93-101.

27. Benjamin M, Evans EJ, Copp L. The histology of tendon attachments to bone in man. J Anat 1986;149:89-100.

28. Chao $\mathbf{E}$, Inoue N, Ikeda K, Aro H, Frassica F. Formation of a pseudo-subchondral bone plate for tendon attachment to metallic implant via osteoinduction. Trans Orthop Res Soc 1997;22(supply 1):1.

29. Korvick DL, Cummings JF, Grood ES, et al. The use of an implantable force transducer to measure patellar tendon forces in goats. J Biotech 1996;29: 557-61.

30. Woo SL-Y, Gomez MA, Sites TJ, et al. The biomechanical and morphologica changes in the medial collateral ligament of the rabbit after immobilization and remobilization. J Bone Joint Surg [Am] 1987;69-A:1200-11.
31. Oguma H, Murakami G, Takahashi-Iwanaga H, Aoki M, Ishii S. Early anchoring collagen fibres at the bone-tendon interface are conducted by woven bone formation: light microscope and scanning electron microscope observation using a canine model. J Orthop Res 2001;19:873-80.

32. Qin TW, Yang ZM, Wu ZZ, et al. Adhesion strength of human tenocytes to extracellular matrix component-modified poly(DL-lactide-co-glycolide) substrates. Biomaterials 2005;26:6635-42

33. Yang J, Yamato M, Kohno C, et al. Cell sheet engineering: recreating tissues without biodegradable scaffolds. Biomaterials 2005;26:6415-22

34. Cao Y, Liu Y, Shan Q, et al. Bridging tendon defects using autologous tenocyte engineered tendon in a hen model. J Plast Recon Surg 2002;110:1280-9.

35. Sato M, Maeda M, Kurosawa $\mathbf{H}$, et al. Reconstruction of rabbit Achilles tendon with three bioabsorbable materials: histological and biomechanical studies. J Orthop Sci 2000;5:256-67. 